\title{
The formation of ultra-fine particles during ozone-initiated oxidations with terpenes emitted from natural paint
}

\author{
Rheo B. Lamorena ${ }^{a}$, Sang-Guen Jung ${ }^{b}$, Gwi-Nam Bae ${ }^{b}$, Woojin Lee ${ }^{a}$ * \\ a Department of Civil and Environmental Engineering, Korea Advanced Institute of Science and Technology, \\ 373-1 Guseong-Dong, Yuseong-Gu, Daejeon 305-701, Republic of Korea \\ ${ }^{\mathrm{b}}$ Environment and Process Technology Division, Korea Institute of Science and Technology, \\ P.O. Box 131, Cheongryang, Seoul 130-650, Republic of Korea
}

Received 19 April 2006; received in revised form 28 June 2006; accepted 29 June 2006

Available online 4 July 2006

\begin{abstract}
The formation of secondary products during the ozone-initiated oxidations with biogenic VOCs emitted from natural paint was investigated in this study. Mass spectrometry and infrared spectroscopy measurements have shown that the major components of gas-phase chemicals emitted from natural paint are monoterpenes including $\alpha$ - and $\beta$-pinenes, camphene, $p$-cymene, and limonene. A significant formation of gaseous carbonyl products and nano-sized particles $(4.4-168 \mathrm{~nm})$ was observed in the presence of ozone. Carboxylic acids were also observed to form during the reactions (i.e. formic acid at $0.170 \mathrm{ppm}$ and acetic acid at $0.260 \mathrm{ppm}$ ). The formation of particles increased as the volume of paint introduced into a reaction chamber increased. A secondary increase in the particle number concentration was observed after 440 min, which suggests further partitioning of oxidation products (i.e. carboxylic acids) into the particles previously existing in the reaction chamber. The growth of particles increased as the mean particle diameter and particle mass concentrations increased during the reaction. The experimental results obtained in this study may provide insight into the potential exposure of occupants to irritating chemical compounds formed during the oxidations of biogenic VOCs emitted from natural paint in indoor environments.
\end{abstract}

(C) 2006 Elsevier B.V. All rights reserved.

Keywords: Ultra-fine particle; Carboxylic acid; Monoterpenes; Ozone-initiated oxidation; Natural paint

\section{Introduction}

Ultra-fine particles of a very low particle mass in the atmosphere represent a higher particle number concentration, such that they greatly outnumber particles larger than $100 \mathrm{~nm}$ given the same particle mass. These ultra-fine particles generally have a high alveolar deposition fraction, a large surface area, and a chemical composition that makes them irritating to humans (with carbonaceous or oxygenated compounds). Thus, if inhaled, they can easily cause adverse health effects (e.g. inflammation of respiratory system). Animal studies and in vitro cell studies have shown that high concentrations of ultra-fine particles can induce inflammatory processes by producing a reactive oxidant species $\left(\mathrm{H}_{2} \mathrm{O}_{2}, \mathrm{O}_{2}^{-}\right)$and by carrying toxic gases and substances into the lung periphery $[1,2]$.

\footnotetext{
* Corresponding author. Tel.: +82 42869 3624; fax: +82 428693610 . E-mail address: woojin_lee@kaist.ac.kr (W. Lee).
}

The formation of secondary ultra-fine particles through the reaction of ozone and several biogenic hydrocarbons (e.g. monoterpenes) has been investigated [3-5]. These monoterpenes can be emitted from indoor cleaners, fragrances, and paint, as well as other consumer products [6-8]. Ozone has been monitored in indoor environments, and its sources have been reported from outdoor infiltration in addition to indoor sources such as air ionizers, photocopiers, and laser printers [9]. Regulations for the restriction of toxic VOC emissions in indoor environments have been recommended manufacturers in order that they may utilize environment-friendly natural products as raw materials for alternatives to toxic anthropogenic chemicals such as xylene and toluene. Some of the raw materials used in these consumer products, such as natural paint, contain monoterpenes. Thus, the natural paint used on walls and on woodwork can be a potential source of monoterpenes in indoor environments. The emitted terpenes from natural paint can react with indoor ozone and generate gaseous and particulate secondary organic products. Studies have shown that the transformation products formed dur- 
ing terpene/ozone oxidations have low vapor pressures and can self-nucleate and/or condense onto previously existing particles $[10,11]$. It is expected that the formation of secondary ultra-fine particles occurs during the ozonation of monoterpenes such as $\alpha$-pinene and limonene [12]. The presence of these oxidation products in particles and onto particle surfaces poses a health risk in indoor environments. Few studies have been conducted to identify the formation of ultra-fine (nano-sized) particles during the atmospheric oxidant-initiated oxidation of biogenic hydrocarbons emitted from indoor materials. Thus, the influence of the ozone concentration and paint volume on the formation of ultra-fine particles during the ozone-initiated oxidations with terpenes emitted from natural paint is investigated in this study.

\section{Experimental section}

\subsection{Chemicals}

The following chemicals used for the experiments and analyses of target monoterpenes and products were American Chemical Society (ACS) or higher grades: $\alpha$-pinene $(98 \%$, Sigma-Aldrich), $\beta$-pinene (99\%, Sigma-Aldrich), limonene (97\%, Sigma-Aldrich), $p$-cymene (99\%, Sigma-Aldrich), camphene (95\%, Sigma-Aldrich), formic acid (85\%, Wako), acetic acid (99.7\%, J.T. Baker), and carbonyl standard mixture (formaldehyde: $215 \mu \mathrm{g} / \mathrm{mL}$, acetaldehyde: $190 \mu \mathrm{g} / \mathrm{mL}$, acetone: $122 \mu \mathrm{g} / \mathrm{mL}$ and propionaldehyde: $122 \mu \mathrm{g} / \mathrm{mL}$, Supelco). The solvents used as eluents and extractants in this research were HPLC or higher grade: acetonitrile (99.8\%, J.T. Baker), pure water (J.T. Baker), and methanol (99.8\%, J.T. Baker). Sodium borate and phosphoric acid solutions were prepared by adding exact amounts of sodium borate $(0.0015 \mathrm{M})$ and phosphoric acid $(0.1 \%)$ into pure water, respectively.

Ozone was produced in situ using an ozone generator (Advanced Pollution Instrumentation) equipped with an ultraviolet lamp (Model 401, Advanced Pollution Instrumentation). The natural paint was purchased from a retail store in Seoul, Korea, and the color white was chosen to best avoid a potential photolytic effect on the reactions of the target monoterpenes and products. The natural paint is based on natural resins and plant oils that can be applied for painting any neutral mineral or wooden surfaces.

\subsection{Experimental methods}

Experiments were conducted using two types of reaction chambers. A small batch bag reactor $(5 \mathrm{~L})$ made of Teflon film was used to identify the composition of natural paint and to characterize the ozone-initiated oxidations of monoterpenes emitted from natural paint. A stainless steel plate $(100 \mathrm{~mm} \times 90 \mathrm{~mm})$ was covered with $5 \mathrm{~mL}$ of natural paint, placed into a small batch bag, and fixed onto the center at one side. The small bag was rapidly sealed using an impulse heat sealer (Model-PI-G, Packaging Aids Corporation), filled with nitrogen (99.999\%, Sinyang Co.), and was allowed to emit biogenic VOCs at room temperature $(22 \pm 0.5)$ for $24 \mathrm{~h}$. It had one port located at the center of the side opposite to the plate for the introduction and sampling of gases. The atmosphere (2L) in the bag was sampled for the identification and quantification of monoterpenes emitted from the natural paint.

A reaction chamber $\left(1 \mathrm{~m}^{3}\right)$ made of Teflon film was utilized to investigate the effects of the oxidant and target monoterpene concentrations on the formation of secondary products. This was done by continuously monitoring the gaseous products and particles during the ozone-initiated reactions under different experimental conditions. Two different volumes of paint (10 and $30 \mathrm{~mL}$ ) and five levels of ozone (50, 100, 200, 500, and $1000 \mathrm{ppb})$ were used in this experiment. Natural paint was applied onto a $300 \mathrm{~mm} \times 300 \mathrm{~mm} \times 5 \mathrm{~mm}$ stainless steel plate. This was dried for $8 \mathrm{~h}$ in an ambient atmosphere and installed onto a stainless steel holder at the bottom of the chamber. The atmosphere outside of laboratory was purified by a clean air system consisting of charcoal, purafil, and high-efficiency particulate air (HEPA) filters and introduced into the chamber at a flow rate of $50 \mathrm{~L} / \mathrm{min}$ for $20 \mathrm{~min}$. Air leakage from the chamber was checked by monitoring the pressure of the chamber for $24 \mathrm{~h}$ before each experimental run. The paint on the plate was allowed to emit the biogenic VOCs for $24 \mathrm{~h}$ and the reaction started immediately after the continuous introduction of different levels of ozone into the chamber at room temperature. The atmosphere inside the chamber was separately and continuously sampled through the outlet ports, and the concentrations of the target terpenes, ozone, and gaseous and particulate products were monitored and determined by analytical equipment (a gas chromatograph with mass spectrometer (GC/MS), a high performance liquid chromatograph (HPLC), an ozone monitor, an ultra condensation particle counter (UCPC) and a scanning mobility particle sizer (SMPS)). After an experimental run, $500 \mathrm{ppb}$ of ozone was introduced into the chamber to remove all impurities inside the chamber. The reaction was allowed to continue for $2 \mathrm{~h}$ and purified air was then introduced, for a duration of $8 \mathrm{~h}$, in order to flush out the atmosphere. The plate surface was washed with alkaline detergent followed by rinsing with tap water; it was then washed with methanol and deionized water. The plate was dried at $220^{\circ} \mathrm{C}$ for $2 \mathrm{~h}$ and cooled in an air atmosphere to prepare it for the next run.

\subsection{Sampling and analysis}

The biogenic VOCs ( $\alpha$ - and $\beta$-pinenes, limonene, camphene, and $p$-cymene) emitted from the natural paint in the $5 \mathrm{~L}$ Teflon bag were measured by a GC/MS (Saturn 2000, Varian) device with a DB-1 column (J\&W Scientific) using an electron impact (EI) mode for ion sources. The temperature of the GC oven was isothermal at $-50^{\circ} \mathrm{C}$ for $7 \mathrm{~min}$; it was then increased to $140^{\circ} \mathrm{C}$ at the rate of $5{ }^{\circ} \mathrm{C} / \mathrm{min}$, and held at that temperature for $15 \mathrm{~min}$. The temperatures of the injection port, ion source, and transfer line were constant at 220,150 , and $170^{\circ} \mathrm{C}$, respectively. Helium $(99.999 \%)$ was used as a carrier gas. The atmosphere in the bag was removed at a flow rate of $5 \mathrm{~L} / \mathrm{min}$, pre-concentrated by a cold sample preparation trap (SPT) for $5 \mathrm{~min}$ at $-150^{\circ} \mathrm{C}$, desorbed at $170^{\circ} \mathrm{C}$, and directly introduced to an injection port at the split ratio of 10:1. The biogenic VOCs were measured by monitoring their mass spectra obtained by continuously scanning ions $(\mathrm{m} / \mathrm{z})$ 
in the range of 30-400. The identification of biogenic VOCs was conducted using dual mass spectrum libraries (National Institute of Standards and Technology (NIST) and 98-Saturn) by comparing the measured mass spectra to those from the libraries.

FT-IR spectroscopy was mainly used to measure the concentrations of target monoterpenes in the batch bag reactors. The FT-IR spectrometer (MTDAC-1400-1F, MIDAC) used in this research was equipped with a $10 \mathrm{~m}$ gas cell (calibrated path length: $9.3 \mathrm{~m}$ ), an $\mathrm{Hg}-\mathrm{Cd}-\mathrm{Te}$ detector, permanently aligned gold-coated mirrors, and $\mathrm{Zn} / \mathrm{Se}$ windows. The detector was cooled by liquid nitrogen, and the temperature of the gas cell was kept constant at $60^{\circ} \mathrm{C}$ during the measurements. Two litres of a gas-phase sample from the reactor was directly introduced into the cell inlet, and its FT-IR spectrum was obtained by averaging 64 scans measured in the range from 650 to $4000 \mathrm{~cm}^{-1}$. The reference absorbance spectra used for the identification and quantification of the target monoterpenes were generated in the authors' laboratory using four different concentrations of target monoterpenes. The spectral regions used for identification and quantification were sought, and were determined to be between 700 and $1100 \mathrm{~cm}^{-1}$. A classical least squares (CLS) technique was used for the quantification and the concentrations of the monoterpenes in addition to the associated CLS errors were automatically calculated through the use of the Autoquant software package (Pro Ver. 4, MIDAC) for each run.

To measure the concentrations of carbonyl compounds (formaldehyde, acetaldehyde, acetone and propionaldehyde) for the investigation of gaseous product formation during the ozoneinitiated oxidations, the atmosphere in the reaction chamber was sampled through an ozone scrubber (Sep-pak ${ }^{\circledR}$, Waters) and by a 2,4-dinitrophenylhydrazine coated silica cartridge (Supelco). Carbonyl compounds in the atmosphere were adsorbed in the cartridge during the sampling and then eluted with the addition of $5 \mathrm{~mL}$ of acetonitrile. An aliquot of extractant $(20 \mu \mathrm{L})$ was introduced into the injection port of an HPLC (Waters) equipped with an ultraviolet (UV) detector and a Nova-Pak C18 column (Waters). The mixture of acetonitrile and ultrapure water $(55 / 45, \mathrm{v} / \mathrm{v})$ was used as a mobile phase and passed through the column with temperature of $25^{\circ} \mathrm{C}$ at a constant rate of $1.0 \mathrm{~mL} / \mathrm{min}$. The concentrations of carbonyls in the extractant were measured using an internal standard method at a wavelength of $360 \mathrm{~nm}$. Carboxylic acids (formic and acetic acids) were sampled through charcoal tubes (Supelco). They were desorbed with $1.5 \mathrm{mM}$ of a borate solution, and an aliquot amount of the extractant $(100 \mu \mathrm{L})$ without concentration was introduced into the injection port of the HPLC equipped with a UV detector at a wavelength of $215 \mathrm{~nm}$ and an Atlantis $\mathrm{C} 18$ column (Waters). A mobile phase eluent was prepared by spiking $0.1 \% \mathrm{H}_{3} \mathrm{PO}_{4}$ into pure water and passed this through the column at a constant rate of $1 \mathrm{~mL} / \mathrm{min}$ under a constant oven temperature of $40^{\circ} \mathrm{C}$.

The concentration of ozone was measured using an ultraviolet-photometric ozone analyzer (Model 49, Thermo Environmental Instruments Inc.) at a wavelength of $254 \mathrm{~nm}$. The response time of the analyzer was less than $20 \mathrm{~s}$, and the precision and noise levels were both less than $\pm 1 \mathrm{ppb}$. The analyzer was calibrated using an ozone calibrator (Model 401, API) before each run and the concentration of the ozone was moni- tored and recorded at $1 \mathrm{~min}$ intervals by an on-line computing system.

A SMPS equipped with an electrostatic classifier (Model 3080, TSI) with a nano-differential mobility analyzer (NDMA, Model 3085, TSI), an ultra-fine condensation particle counter (UCPC, Model 3025, TSI), and an impactor nozzle $(0.0457 \mathrm{~cm})$ was used for the monitoring of particle diameter, particle mass, and particle number concentration in the reaction chamber in order to investigate the nucleation of particles during the reaction and to identify the effect of the concentrations of oxidant and monoterpenes on the formation of particles. The gas-phase sample in the reaction chamber was sampled at a flow rate of $0.3 \mathrm{~L} / \mathrm{min}$, directly introduced to the SMPS under a constant sheath flow of $3.0 \mathrm{~L} / \mathrm{min}$, and scanned at a time resolution of $5 \mathrm{~min}$ ( $240 \mathrm{~s}$ for up-scan and $30 \mathrm{~s}$ for down-scan). The particles of a gas-phase sample in the range of 4.4-168 nm were used for the SMPS measurement. The UCPC was at times solely operated for the measurement of the particle number concentration. When this occurred, the particle number concentration was monitored by measuring the particles greater than $3 \mathrm{~nm}$ at a sampling flow rate of $0.03 \mathrm{~L} / \mathrm{min}$ and at a response time of $1 \mathrm{~s}$.

\section{Results and discussion}

\subsection{Identification of VOCs emitted from natural paint}

Paint manufacturers have commonly used rosemary, eucalyptus, and orange oils as a source of essential oils in an effort to add fragrance to natural paint. This could result in significant emissions of monoterpenes, esters, and alcohols into indoor environments [13-16]. The monoterpenes that were quantified and identified were $\alpha$-pinene, camphene, $\beta$-pinene, $p$-cymene, and limonene. The respective concentrations and detection limits of monoterpenes are given in Table 1. This result confirms that the biogenic VOCs emitted from the natural paint are mainly composed of the five monoterpenes identified above. Therefore, a characterization study for the ozone-initiated oxidations with VOCs emitted from natural paint was carried out by focusing on the investigation of oxidations with these five target monoterpenes.

Table 1

List of identified and quantified organic chemicals and corresponding detection limits

\begin{tabular}{llc}
\hline Compounds & $\begin{array}{l}\text { Detected concentrations } \\
(\mathrm{ppm})\end{array}$ & $\begin{array}{l}\text { Detection limits } \\
(\mathrm{ppm})\end{array}$ \\
\hline$\alpha$-Pinene & 0.828 & 0.012 \\
$\beta$-Pinene & 0.405 & 0.004 \\
Camphene & 1.45 & 0.006 \\
$p$-Cymene & 0.018 & $<0.001$ \\
Limonene & 0.162 & 0.004 \\
Acetaldehyde & 0.040 & 0.004 \\
Acetone & $0.003-0.095$ & 0.001 \\
Formaldehyde & $0.033-0.086$ & 0.002 \\
Propionaldehyde & 0.045 & 0.005 \\
Acetic acid & 0.260 & 0.006 \\
Formic acid & 0.170 & 0.002 \\
\hline
\end{tabular}




\subsection{Formation of gaseous products}

It has been known that the ozone-initiated oxidation of terpenes produces primarily a carbonyl and an energy-rich criegee intermediate. Both products may undergo further oxidation reactions producing a variety of multifunctional compounds (e.g. conjugated organic acids and carbonyls) [10,11]. The low molecular carbonyls, including formaldehyde, acetaldehyde, acetone, and propionaldehyde were observed to form during the oxidation reactions. The concentrations of carbonyl products monitored during the reactions were formaldehyde, acetaldehyde, acetone, and propionaldehyde; the measured concentrations as well as the detection limits are shown in Table 1. The formation of these gaseous compounds is consistent with previous investigations by other research groups $[10,11]$. Other oxidation products identified during the reactions were formic and acetic acids. No acetic and formic acids were observed early in the experiments, and the formation abruptly increased to 0.260 and $0.170 \mathrm{ppm}$ immediately after 6 and $9 \mathrm{~h}$, respectively. The high concentrations of carboxylic acids generated from the experiment may have resulted from the presence of water vapor that may have evolved from the water-based paint inside the bag. The paint might not have totally "dried" after $8 \mathrm{~h}$ of drying in ambient air, thus potentially contributing to homogeneous and heterogeneous reactions as well. Studies have shown that criegee intermediates can react with surrounding water molecules. Criegee intermediates have long been postulated as important species in ozone/terpene oxidation reactions. The simple or smallest criegee intermediate that could form in the ozonation of monoterpenes like $\beta$-pinene is $+\mathrm{CH}_{2}-\mathrm{O}-\mathrm{O}-$. Simple criegee intermediates (e.g. $+\mathrm{CH}_{2}-\mathrm{O}-\mathrm{O}-$ ) have been shown to react with water to give carboxylic acids and $\alpha$-hydroxy-hydroperoxides [17-20]. It was suggested that the reaction occur via the following mechanism:

$$
\begin{aligned}
+\mathrm{CH}_{2}-\mathrm{O}-\mathrm{O}-+\mathrm{H}_{2} \mathrm{O} & \rightarrow \mathrm{CH}_{2}(\mathrm{OH}) \mathrm{OOH} \\
& \rightarrow \mathrm{HCOOH}+\mathrm{H}_{2} \mathrm{O}
\end{aligned}
$$

The presence of these carboxylic acids strongly indicates that other high-molecular weight oxidation products have additionally formed from the degradation of monoterpenes in the reaction chamber. Once these low-volatile products exceed their saturation vapor pressures, the nucleation of particles starts to occur. It is known that high humidity reduces particle formation during ozonolysis, but the particles formed during the reaction may serve as adsorption sites for the partitioning of less volatile products [18]. The water in the reaction chamber could potentially affect the formation of particles in the system utilized in this study. Unfortunately, the effect of humidity was not evaluated on the formation of particles in the reaction chamber.

\subsection{Formation of particles}

The role of monoterpenes and ozone interaction in particle formations has been reported in several investigations. Lowvolatile oxidation products are believed to self-nucleate, and semi-volatile products partition onto existing particle surfaces [21-23]. In this study, particle formation was monitored in all experimental runs. The concentration profiles of the particles under different experimental conditions, as monitored via UCPC, are presented in Fig. 1. A rapid increase in particle number concentration was observed after ozone was introduced into the chamber, and it decreased over time. The increase in the particle number concentration under a high concentration of ozone (500 and $1000 \mathrm{ppb}$ ) was observed $10 \mathrm{~min}$ after the addition of ozone into the reaction chamber, as shown in Fig. 1a, while the increase in the particle number concentration under lower ozone concentrations $(50,100$, and $200 \mathrm{ppb}$ ) were delayed, being observed approximately $25 \mathrm{~min}$ after the ozone addition. This indicates that the initiation rate of particle formation is influenced by the ozone concentration while it is independent of the natural paint concentration in this experiment. The observed time lag of $15 \mathrm{~min}$ for the particle formation between the high and low ozone concentrations reflects a delay of the generation of condensed particles under low ozone concentrations. This observed time lag has also been observed in other smog chamber studies. This suggests that air exchange rates are crucial in real indoor environments, so as to delay and reduce particle formations by diluting the concentration of ozone in indoor environments.

In contrast to the initiation rate, the variation in the particle number concentrations with respect to time appears to be affected by both the concentrations of ozone and natu-
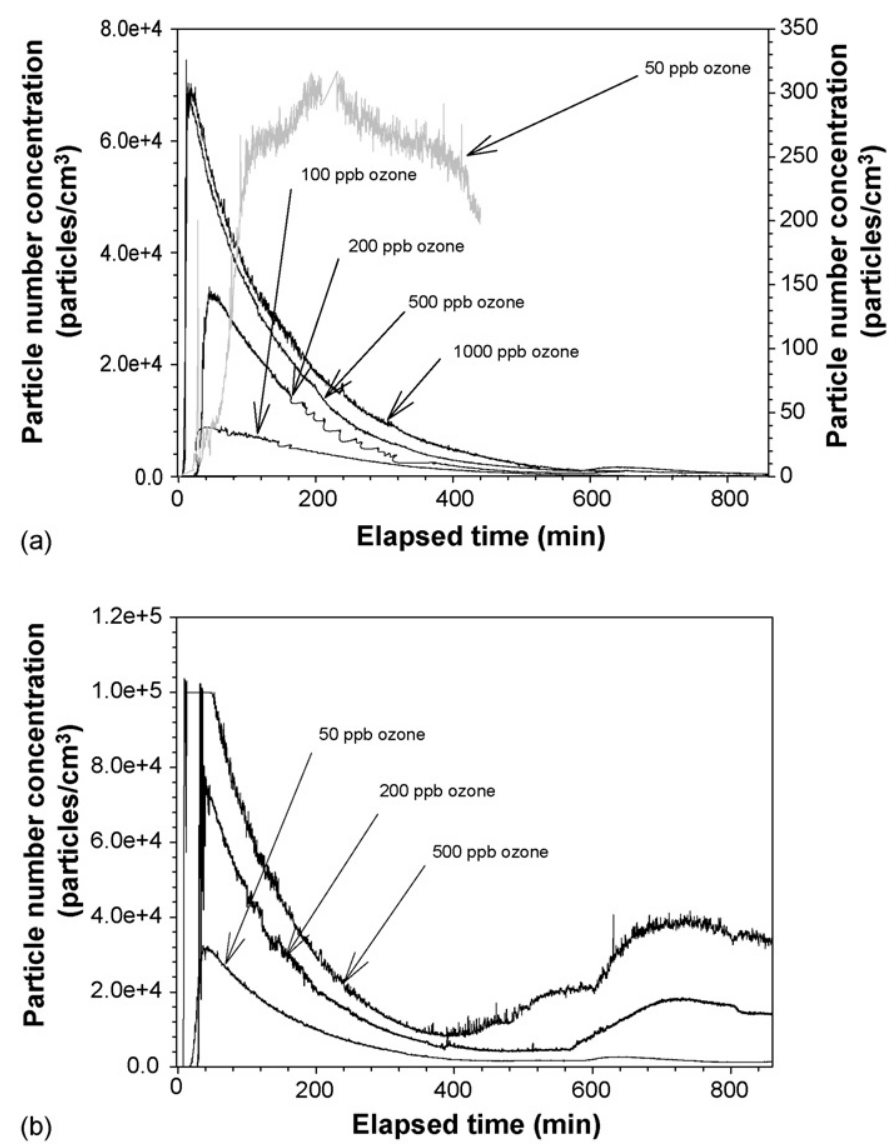

Fig. 1. Variation of particle number concentrations during the ozone-initiated oxidations at different ozone concentrations (50,100, 200, 500, and $1000 \mathrm{ppb}$ ) and different volumes of paint (a) $10 \mathrm{~mL}$ and (b) $30 \mathrm{~mL}$. 
ral paint. The particle number concentration was highly correlated with the ozone concentration. The maximum particle number concentration $\left(>100,000\right.$ particles $\left./ \mathrm{cm}^{3}\right)$ was found at $500 \mathrm{ppb}$ of ozone with $30 \mathrm{~mL}$ of natural paint, and the minimum (300 particles $/ \mathrm{cm}^{3}$ ) was found at $50 \mathrm{ppb}$ with $10 \mathrm{~mL}$ of natural paint. The maximum concentration cannot be precisely measured due to the upper detection limit of CPC $\left(<100,000\right.$ particle $\left./ \mathrm{cm}^{3}\right)$. The particle number concentrations at different ozone concentrations with $10 \mathrm{~mL}$ of natural paint decreased immediately after reaching the maximum particle number concentrations, which may be due primarily to the particle growth caused by the condensation of particles formed during oxidation. The wall loss due to the sorption of particles onto the Teflon film of the reaction chamber may have also been a potential sink source for the decrease in the particle number concentration.

In comparison to the ozone-initiated oxidations with $10 \mathrm{~mL}$ of paint showing a continuous decrease in number concentrations throughout the experiment run, a different concentration profile was observed for the oxidations with $30 \mathrm{~mL}$ of paint shown in Fig. 1b. The increase of particles starting at 440, 570, and $600 \mathrm{~min}$ for each profile suggests that some reaction mechanism or mechanisms other than condensation contributed to the growth of particles. It is possible that the homogenous nucleation of one or more oxidation products with low vapor pressures occurred, resulting in a sudden increase in the number of nuclei serving as condensation sites. The secondary increase in particle number concentrations suggests that the formation of particles may increase from the partitioning of secondary gaseous products (e.g. pinic acid and limonic acid) to a solid phase during the ozone-initiated oxidations with monoterpenes emitted from the natural paint. This observation could be correlated to the increase in carboxylic acids that was observed in the gas-phase analysis. The presence of these low molecular carboxylic acids indicates that larger but less volatile molecules were formed during the oxidation and that some products can consequently decompose into acetic and formic acids [24,27]. It is also possible that these low molecular weight compounds can partition into a particle phase. Researchers have found acetic and formic acids in secondary ultra-fine particles during field and smog chamber measurements [25-27].

The particle number concentrations decreased slowly after the secondary peak values, implying that the rate of particle growth was slightly greater than that of particle formation at this stage. This implies that additional condensable and low-volatile organic compounds form during the reaction while the volatile species will remain in a gas-phase. It further suggests that the potential inhalation of these particles and volatile species formed during the reactions can cause serious respiratory problems.

The ozone reactions significantly affected the formation of particles during the ozone-initiated oxidation with target monoterpenes emitted from the natural paint. The formation of nano-sized particles $(4.4-168 \mathrm{~nm})$ was observed in this study during the oxidation. The initiation of particle formation was monitored between 5 and $10 \mathrm{~nm}$, which implies that the partitioning and/or saturation for the nucleation of particles can occur at less than $10 \mathrm{~nm}$. This result is consistent with the experimental work conducted by Rohr et al. and Sarwar et al. [3,4]. Fig. 2a-c shows the particle size distribution monitored by SMPS, the variation in the mean particle diameter during the ozone-initiated oxidation, and relationship between the particle number concentration and total particle mass concentration $(500 \mathrm{ppb}$ of ozone and $10 \mathrm{~mL}$ of paint), respectively. The curve in Fig. 2a shows a particle size distribution which was scanned for $5 \mathrm{~min}$. The area under the curve represents the total particle number con-
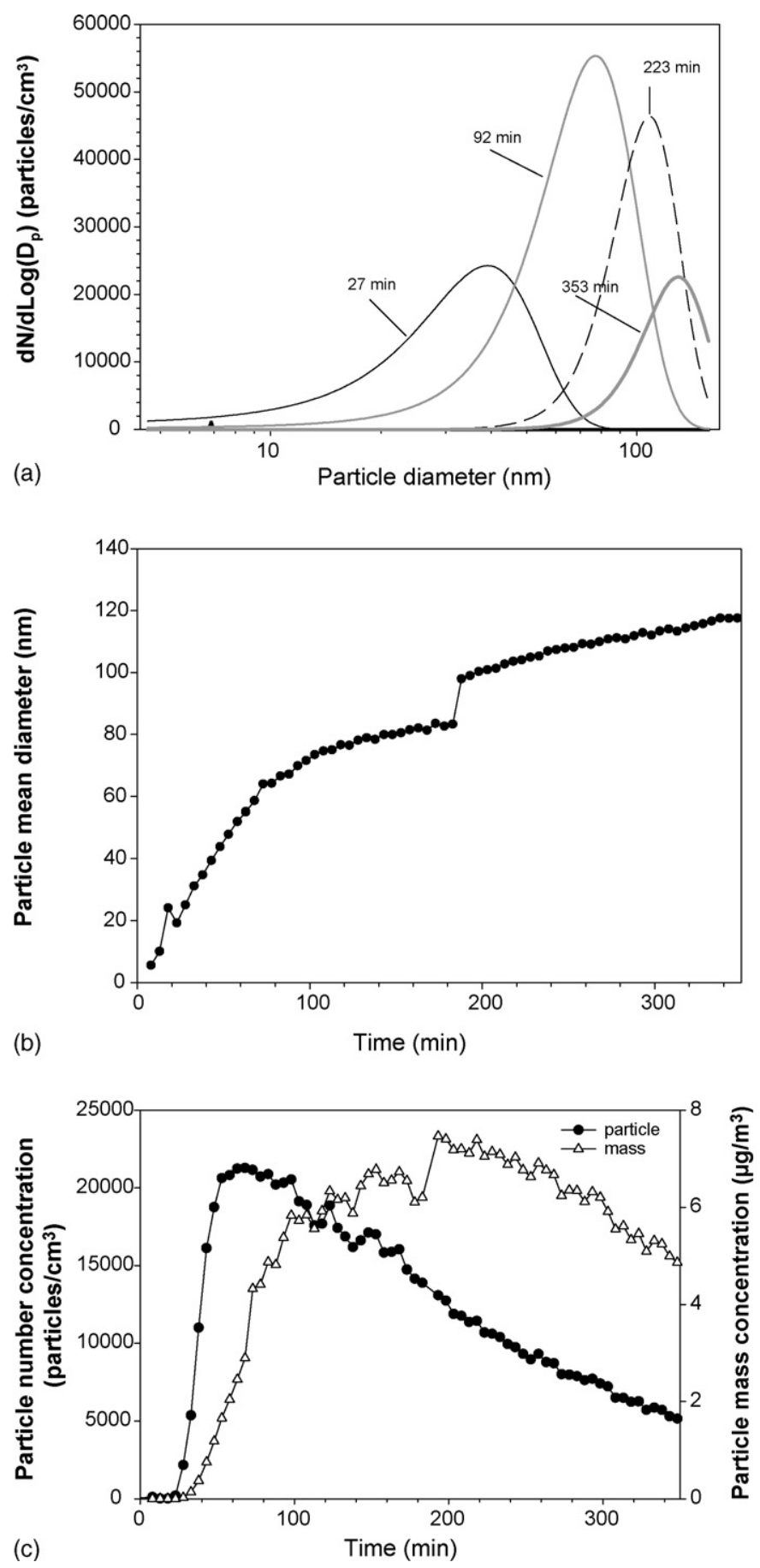

Fig. 2. Characterization of the particle formation: (a) particle size distribution by monitoring SMPS; (b) change in mean particle diameter during ozone reactions; (c) particle number concentration and total particle mass concentration. The experimental condition was under $500 \mathrm{ppb}$ of ozone and $10 \mathrm{~mL}$ of paint 
centration. The profile shown in Fig. 2a shows the particle size (or number concentration) within the size range of $\mathrm{d} D_{\mathrm{p}}\left(D_{\mathrm{p}}\right.$ to $D_{\mathrm{p}}+\mathrm{d} D_{\mathrm{p}}$ ) plotted against the particle diameter. The total particle number concentration decreased as a particle diameter having a maximum particle number concentration at each scanned time increased, which is essentially due to the particle growth caused by the condensation of particles and further caused by the partitioning of SVOCs (semi-volatile organic carbons) formed during the ozone-initiated oxidation. The peak particle number concentration at each distribution curve reached the maximum concentration at $92 \mathrm{~min}(70 \mathrm{~nm})$. It then decreased as the reaction proceeded, shifting toward a larger particle diameter (i.e. $120 \mathrm{~nm}$ at $353 \mathrm{~min}$ ). Fig. $2 \mathrm{~b}$ shows the increase in the mean particle diameter during the ozone-initiated oxidation, indicating that the particle growth continued until the particle diameter reached $120 \mathrm{~nm}$. It has been reported that the particles can grow until they reach $1 \mu \mathrm{m}$ during the reaction [27]. Fig. 2c shows a correlation between the particle number concentration and the total particle mass concentration during the ozone-initiated oxidation. A rapid increase in the particle number concentration was observed at an early time. The particle number concentration reached the maximum number concentration at approximately $60 \mathrm{~min}$ and then slowly decreased as the reaction proceeded. The particle mass concentration rapidly increased from 20 to $100 \mathrm{~min}$ and then gradually increased as the reaction proceeded. Weschler and Shields measured the average mass concentrations $\left(2.5-5.5 \mu \mathrm{g} / \mathrm{m}^{3}\right)$ in terpene/ozone reactions in typical indoor environmental conditions [27]. The total mass concentration monitored in the present experiment was $0-7.4 \mu \mathrm{g} / \mathrm{m}^{3}$, which is fairly consistent with the measurements of Weschler and Shields. The gradual increase observed in the figure suggests that less volatile organic compounds partition into particles. Consequently, an accumulation of the particles occurs, thus contributing to the particulate mass. The subsequent decrease in the particle number and mass concentrations after the rapid increase of both concentrations appears to be due primarily to the particle growth caused by the condensation of particles during the oxidation in addition to the wall loss caused by the sorption of particles onto the Teflon film, which may be a potential sink during the reaction.

\subsection{Summary and conclusions}

Low molecular carbonyls such as formaldehyde, acetone, and acetaldehyde, in addition to carboxylic acids were observed as secondary products during the ozone-initiated reactions with the biogenic hydrocarbons emitted from natural paint. The particles formed during the ozone-initiated reaction of terpenes emitted from natural paint are nano-particles in size and much smaller than $\mathrm{PM}_{2.5}$ and $\mathrm{PM}_{10}$, which can pose a significant health concern. The maximum mass concentration of the particles formed during the reactions is much lower than the particle pollution levels proposed by the Environmental Protection Agency $\left(\mathrm{PM}_{10}\right.$ : $150 \mu \mathrm{g} / \mathrm{m}^{3}$ in $24 \mathrm{~h}$ and $\mathrm{PM}_{2.5}: 65 \mu \mathrm{g} / \mathrm{m}^{3}$ in $24 \mathrm{~h}$ ); however, particle pollutant levels for finer particles and those for in indoor environments have not been proposed to date. More research needs to be carried out concerning the adverse health effects of finer particles formed during similar reactions in indoor environments. Most of the ozone concentrations applied during the experimental runs were very high compared to normal indoor environments (10-100 ppb) [9]. Therefore, the results obtained may be overestimated. Nonetheless, the results obtained from this study can contribute to the awareness of the formation of toxic secondary gaseous products and nano-sized particles during the ozone-initiated oxidation of terpenes emitted from indoor materials in real environments. The results can also be applied for a determination of a reducing strategy and in control technology of toxic indoor pollutants emitted and formed in indoor environments. Moreover, the results can contribute to the development of environmental policies for public health and safety.

\section{Acknowledgements}

This research was supported by the grants from the Korean Ministry of Environment (Eco-technopia 21; 2M14480) and the Korea Institute of Science and Technology (2V200710). The contents do not necessarily reflect the views and policies of the sponsors nor does the mention of trade names or commercial products constitute endorsement or recommendation for use.

\section{References}

[1] P.S. Vinzents, P. Moller, M. Sorensen, L.E. Knudsen, O. Hertel, F.P. Jensen, B. Schibye, S. Loft, Personal exposure to ultrafine particles and oxidative DNA damage, Environ. Health Perspect. 113 (2005) 1485-1490.

[2] G. Oberdorster, E. Oberdorster, J. Oberdorster, Nanotoxicology: an emerging discipline evolving for studies of ultrafine particles, Environ. Health Perspect. 113 (2005) 823-839.

[3] M.G. Sarwar, D. Olson, R. Corsi, C.J. Weschler, Indoor fine particles: the role of terpene emissions from consumer products, J. Air Waste Manage. Assoc. 54 (2004) 367-377.

[4] A.C. Rohr, C.J. Weschler, P. Koutrakis, J.D. Spengler, Generation and quantification of ultrafine particles through terpene/ozone reaction in a chamber setting, Aerosol. Sci. Technol. 37 (2003) 65-78.

[5] T. Wainman, J. Zhang, C.J. Weschler, P.J. Lioy, Ozone and limonene in indoor air: a source of submicron particle exposure, Environ. Health Perspect. 108 (2000) 1139-1145.

[6] C.M. Long, H.H. Suh, P. Koutrakis, Characterization of indoor particle sources using continuous mass and size monitors, J. Air Waste Manage. Assoc. 50 (2000) 1236-1250.

[7] C.J. Weschler, Chemical reactions among indoor pollutants: what we've learned in the new millennium, Indoor Air 14 (2004) 184-194.

[8] C.J. Weschler, H.C. Shields, Potential reactions among indoor pollutants, Atmos. Environ. 31 (1997) 3487-3495.

[9] C.J. Weschler, Ozone in indoor environments: concentration and chemistry, Indoor Air 10 (2000) 269-288.

[10] R. Atkinson, J. Arey, Gas-phase tropospheric chemistry of biogenic volatile organic compounds: a review, Atmos. Environ. 37 (Suppl. 2) (2003) S197-S219.

[11] A. Calogirou, B.R. Larsen, D. Kotzias, Gas-phase terpene oxidation products: a review, Atmos. Environ. 33 (1999) 1423-1439.

[12] T. Hoffmann, J.R. Odum, F. Bowman, D. Collins, D. Klockow, R.C. Flagan, J.H. Seinfeld, Formation of organic aerosols from the oxidation of biogenic hydrocarbons, J. Atmos. Chem. 26 (1997) 189-222.

[13] C. Boutekedjiret, F. Bentahar, R. Belabbes, J.M. Bessiere, Extraction of rosemary essential oil by steam distillation and hydrodistillation, Flavour Frag. J. 18 (2003) 481-484.

[14] B.D. Moore, I.R. Wallis, J. Pala-Paul, J.J. Brophy, R. Willis, W.J. Foley, Antiherbivore chemistry of eucalyptus - cues and deterrents or marsupial folivores, J. Chem. Ecol. 30 (2004) 1743-1769. 
[15] R.C. Muhlbauer, A. Lozano, S. Palacio, Common herbs, essential oils, and monoterpenes potently modulate bone metabolism, Bone 32 (2003) 372-380.

[16] A. Orav, J. Kannm, Determination of peppermint and orange aroma compounds in food and beverages, Proc. Estonian Acad. Sci. Chem. 50 (2001) 217-225.

[17] X. Liu, M. Mason, K. Krebs, L. Sparks, Full-scale chamber investigation and simulation of air freshener emissions in the presence of ozone, Environ. Sci. Technol. 38 (2004) 2802-2812.

[18] B. Bonn, G. Schuster, G.K. Moortgat, Influence of water vapor on the process of new particle formation during monoterpene ozonolysis, J. Phys. Chem. A 106 (2002) 2869-2881.

[19] M. Jang, N.M. Czoschke, S. Lee, R.M. Kamens, Heterogeneous atmospheric aerosol production by acid-catalyzed particle phase reactions, Science 298 (2002) 814-817.

[20] P. Neeb, F. Sauer, O. Horie, G.K. Moortgat, Formation of hydroxymethyl hydroperoxide and formic acid in alkene ozonolysis in the presence of water vapor, Atmos. Environ. 31 (1997) 1417-1423.

[21] J. Zhang, W.E. Wilson, P.J. Lioy, Indoor air chemistry: formation of organic acids and aldehydes, Environ. Sci. Technol. 28 (1994) 1975-1982.
[22] S. Koch, R. Winterhalter, E. Uherek, A. Kollof, P. Neeb, G.K. Moortgat, Formation of new particles in the gas-phase ozonolysis of monoterpenes, Atmos. Environ. 34 (2000) 4031-4042.

[23] C.K. Wilkins, P. Wolkoff, P.A. Clausen, M. Hammer, G.D. Nielsen, Upper airway irritation of terpene/ozone oxidation products (TOPS). Dependence on reaction time, relative humidity and initial ozone concentration, Toxicol. Lett. 143 (2003) 109-114.

[24] M. Galsius, M. Lahaniati, N.R. Jensen, J. Hjorth, D. Kotzias, B.R. Larsen, Carboxylic acids in secondary aerosols from oxidation of monoterpenes with ozone, Environ. Sci. Technol. 34 (2000) 1001-1010.

[25] M. Legrand, S. Preunker, B. Jourdain, B. Aumont, Year-round records of gas and particulate formic and acetic acids in the boundary layer at Dumont d' Urville, coastal Antarctica, J. Geophys. Res. 109 (2004) D06313.

[26] U. Baltensperger, M. Kalberer, J. Dommen, D. Paulsen, M.R. Alfarra, H. Coe, R. Fisseha, A. Gascho, M. Gysel, S. Nyeki, M. Sax, M. Steinbacher, A.S.H. Prevot, S. Sjogren, E. Weingartner, R. Zenobi, Secondary organic aerosols from anthropogenic and biogenic precursors, Faraday Discuss. 130 (2005) 265-278.

[27] C.J. Weschler, H.C. Shields, Indoor ozone/terpene reactions as a source of indoor particles, Atmos. Environ. 33 (1999) 2301-2312. 